\title{
Prevention of Skeletal Muscle Wasting: Disuse Atrophy and Sarcopenia
}

\author{
Naomi E. Brooks and Kathryn H. Myburgh \\ Additional information is available at the end of the chapter
}

http://dx.doi.org/10.5772/47856

\section{Introduction}

Skeletal muscle plays a considerable role in health and disease. Muscle mass is essential for health and survival and plays a major role in mobility as well as morbidity and mortality. There is continual synthesis and degradation of proteins as part of normal metabolism and homeostasis. Equally remarkable, is the characteristic of plasticity allowing muscle to change and adapt depending on the stimuli and load placed upon it.

Increasing the contractile load on skeletal muscle leads to increased muscle mass and strength typified by that seen with a resistance exercise programme. This can be beneficial for sports performance as well as allowing an individual to improve physical fitness, maintain health status and improve quality of life.

Inactivity, or reduced load, results in a loss of skeletal muscle mass. This loss of muscle mass and corresponding loss of strength and function may lead to a reduced quality of life and life expectancy [1].

The morphological changes associated with muscle atrophy are a decreased cross-sectional area (CSA) of muscle fibres resulting in a reduced muscle mass, but without a decrease in the number of muscle fibres. When the muscle becomes smaller, this leads to reduced muscle strength. In humans, muscle atrophy appears to be a consequence of reduced protein synthesis with no change in protein degradation [2]. Loss of muscle mass is also seen in disease states such as cancer, AIDS, renal failure, congestive heart failure, chronic obstructive pulmonary disease (COPD) and burns. In addition to disuse, disease-induced muscle loss (cachexia) also involves a complex interplay of cytokine and inflammatory responses.

Disuse is a broad descriptor of the mechanical unloading of the muscle; with the most extreme example being that of spaceflight. Far more common life events, such as immobilisation, bed 
rest or disuse also include decreased mechanical loading. Perhaps most common is the lack of regular mechanical loading that accompanies sedentary behaviour. Changes seen with disuse/inactivity do not include an increase in inflammatory or cytokine response such as that seen in disease state cachexia.

In this book chapter we will discuss various conditions which lead to skeletal muscle atrophy. The excitement generated by spaceflight led many researchers to study physiological effects influencing the astronaut who has to function in an atmosphere of no gravity. The most common simulation of spaceflight is ground based bed rest. While an individual is placed in the horizontal position, the changes noted are not completely identical to spaceflight since the astronaut conducts normal daily tasks while the individual on bed rest must restrict their movements. Physiological changes during bed rest include decreases in muscle mass and strength and other disuse associated changes in skeletal muscle. If the bed rest is at a $6^{\circ}$ head down tilt angle, the individual will experience equivalent fluid shifts to that seen in spaceflight.

A number of immobilisation techniques have been identified to investigate disuse and load reduction on skeletal muscle. Unilateral lower limb suspension (ULLS) involves one limb being suspended while the other is used for movement assisted by crutches. Since the suspended leg cannot move, muscle mass loss is observed. Similarly, a limb immobilised by a leg brace or cast also loses muscle mass due to disuse.

A rodent model of disuse, hindlimb suspension, also leads to significant skeletal muscle atrophy. The model involves the animals supporting their weight on their front legs and preventing the back legs from bearing any weight because the animal is suspended by the tail. The unloading leads to muscle atrophy and provides a crucial animal model of muscle atrophy to provide insight into the complex interplay of influences on skeletal muscle with inactivity.

The extent of muscle atrophy induced by these models has been reported by Narici and de Boer [3] and a brief summary is provided here:

i. Spaceflight: reductions of total lower limb muscle mass of between 6-24\%.

ii. Animal models of disuse: preferential decreases in muscle fibre size are noted in slow twitch muscles which are usually consistently more activated due to their postural function.

iii. Unilateral lower limb suspension (ULLS) in humans: 5-10\% decrease in quadriceps CSA within 4 weeks [4].

iv. Immobilization (cast or leg brace) in humans: $12 \%$ decrease in leg volume with $46 \%$ decrease in type I fibre size and 37\% decrease in type II fibres [5].

One of the consequences of a shift in fibre type from slower phenotypes (more oxidative) to faster phenotypes (more glycolytic) is the greater fatiguability of the faster fibres. Other changes which occur during inactivity and disuse include metabolic alterations including reduced insulin sensitivity [6], decreased capillary density in both fibre types and a disruption of the skeletal muscle architecture [7]. 
Sarcopenia is the loss of muscle size and strength in the ageing process. There is a gradual decrease in physical function throughout the ageing process. Loss of muscle mass in the elderly is a significant health risk leading to impairment of maximal aerobic capacity, decreased insulin sensitivity, impaired oxidative defense, lower resting metabolic rate and functional dependency (reviewed by $[8,9]$ ). The mechanisms causing sarcopenia are different to those of disuse atrophy even though the reduced activity noted in most elderly individuals does contribute to skeletal muscle loss. There are a number of factors which contribute to the age-associated decrease in size and strength of skeletal muscle, including excessive oxidative stress, degeneration of the neuromuscular junction, fibre denervation/reinnervation, decreased oxidative capacity, hypoplasia of type II fibres, declining hormone levels, and a fast-to-slow fibre type transition.

Skeletal muscle changes associated with ageing begin in the 20 s and decline more rapidly as a person reaches their 50s [10] and this is particularly noted in the lower body [11]. Type II fibre size may be reduced by $20-50 \%$ and although type I fibres are less affected, they may still be $1-25 \%$ decreased in size. The reduction in whole muscle mass is greater than muscle fibre size reduction because of an additional loss of fibres [10,12]. This phenomenon, not seen in disuse atrophy, is a result of progressive degeneration and reinnervation of alpha motorneurons. Denervation leads to loss of fibre number (hypoplasia) contributing to muscle atrophy. With reinnervation, the previously denervated fibres undergo a change in phenotype to the new innervation which results in an increase in number of type I fibres. This specific reduction in numbers of type II fibres is associated with increased coexpression of myosin heavy chain isoforms and fibre grouping ultimately leading to a change in recruitment as well as decreased strength.

Ageing also leads to decreased aerobic capacity, with contributory factors including decreases in stroke volume, heart rate and arterio-venous oxygen difference [13]. Together, the reduced aerobic capacity and loss of skeletal muscle mass contribute to increased morbidity and mortality [14]. Other conditions, also associated with ageing, contribute to sarcopenia, loss of function, morbidity and mortality.

Older adults often have an increased fat mass (sarcopenic obesity) which contributes to various metabolic disorders including diabetes, obesity, and cardiovascular disease; and loss of bone which causes further mobility reductions because of osteoporosis [15]. The increase of fat and non-contractile tissues in the muscle, as well as insulin resistance and reduced muscle metabolism, causes the quality of the remaining muscle in an ageing individual to be reduced [16].

There are many contributing factors to the ageing process which involve hormonal, nutritional, immunological and neural components which create a decreased pro-anabolic environment and an increased catabolic environment. For example, an increased production of cytokines and resulting inflammation. These factors contribute to sarcopenia and result in a further reduction in physical activity, decreased basal metabolic rate (BMR), increased risk of osteoporosis and increased incidence of falls and injury. 
An increase in reactive oxygen species (ROS) over the lifespan also has a significant impact on the ageing process. As the body ages, an increased production of ROS as well as a reduced ability to quench the ROS molecules leads to cellular damage. Further to this detriment, there is a decrease in mitochondrial volume as well as reduced functional ability of the remaining mitochondria. This, in turn, leads to further increases in ROS production. Whereas young muscle is capable of adapting by synthesizing additional enzymes to neutralize oxidative stress, this does not occur sufficiently in older adults, thus there is accumulation of oxidative damage in the cell contributing to further mitochondrial dysfunction and malfunction of other proteins damaged by the free radicals [17].

Muscle cells are the most protein dense of all cells and there are mechanisms in place aimed at protecting and regenerating healthy muscle tissue. During atrophy, these cellular and molecular mechanisms are not able to balance the mechanisms inducing muscle loss.

The next section of this book chapter aims to elucidate:

- cellular mechanisms involved in disuse atrophy and sarcopenia including satellite cells, and myonuclear domain size.

- the most relevant molecular pathways: Myostatin/SMAD pathway; ubiquitin proteasome pathway and the IGF1/mTOR pathway.

Thereafter, the rest of the chapter will:

- Discuss methodological analysis and imaging of skeletal muscle changes with atrophy and sarcopenia (including human and animal models).

- Highlight current knowledge of ways to prevent or alleviate muscle atrophy and sarcopenia including exercise and nutritional interventions.

\subsection{Myonuclear Domain and Atrophy/Sarcopenia}

Skeletal muscle cells are large and one of the few cells in the body which are multinucleated. Each myonucleus governs a surrounding area of cytoplasm, called a myonuclear domain; and muscle fibres are considered to be mosaics of these overlapping myonuclear domains [18]. The myonuclear domain theory suggests that each myonucleus produces enough protein to support a limited amount of cytoplasm and the structural proteins produced are restricted to that domain [19]. If there is need for substantially more proteins, more myonuclei are required, thereby establishing new myonuclear domains as fibres increase in size.

Myonuclei are post-mitotic, but satellite cells can proliferate when required and provide new myonuclei to skeletal muscle fibres. Satellite cells are skeletal muscle stem cells which reside between the basal lamina and sarcolemma of skeletal muscle fibres. They are required for post-natal growth of the fibre [20]. When activated, satellite cells proliferate expressing the early myogenic regulatory factors (MRFs), MyoD and Myf5; thereafter they express the later MRFs, Myogenin and MRF4, differentiate and donate daughter nuclei to the muscle fibre. Satellite cells become activated when adult muscle fibres are stimulated to undergo hypertrophy or regeneration [21]. 
The muscle fibre maintains a relatively constant myonuclear domain size during growth [22]. Increases in CSA are often accompanied by increases in myonuclei $[23,24]$. Based on this theory, with muscle atrophy there should be a decrease in myonuclear number which should correspond with a decrease in CSA, in order to maintain myonuclear domain size. Indeed, atrophy due to microgravity is associated with decreased myonuclear number and a constant myonuclear domain size [7]. However, recent studies of single fibres suggest that nuclear domain may be less consistent than previously thought and it has been suggested that fibres undergoing atrophy do not lose myonuclei [25]. After 28 days of denervation, nerve impulse block or mechanical unloading there was significant muscle fibre atrophy but no loss of myonuclei [26].

Results on myonuclear domain maintenance in ageing muscle are equivocal. In atrophied muscles, concurrent decreases in fibre size and myonuclear number maintain the myonuclear domain size [7]. However, decreases in fibre size without decreases in myonuclear number have also been reported in ageing, leading to a reduced myonuclear domain size. Hikida et al. [27] showed that the nucleus-to-cytoplasm ratio was not maintained in untrained elderly men. In an animal model, Brack et al. [28] found the number of nuclei per unit length decreased in ageing animals, which resulted in an increased myonuclear domain size. They also found larger fibres to have more satellite cells than smaller fibres, but during the ageing process this declined. They postulated that a deficit in satellite cells resulted in the inadequate nuclear replacement seen in ageing muscle.

Myonuclear domain size appears to differ between fibre types [29]. Slow fibres have more myonuclei per unit area [30], leading to a small myonuclear domain size [7,23,31]. Slow fibres have higher rates of protein turnover [32] and a higher oxidative capacity (requiring greater levels of protein synthesis) [33]. Fast glycolytic fibres, with lower oxidative activity, have relatively larger myonuclear domain sizes [29,31].

Investigations examining changes in myonuclear domain size in ageing skeletal muscle, at least in slow and fast type muscle in rodents, have revealed an increase in number of myonuclei in slow fibres resulting in a decrease in myonuclear domain size [34]. This is perhaps due to a reduced functional ability of the nuclei in slow fibres of old muscle. It can be hypothesised that ageing muscle could benefit from the addition of new myonuclei with younger attributes.

However, research studies examining the effects of ageing on satellite cells also have been equivocal. During the ageing process, satellite cells may decrease in number [35-37]. Other studies found no reduction in satellite cell numbers in ageing skeletal muscle $[27,38]$. Similar to aged myonuclei, it appears that satellite cells have a decreased functional ability $[39,40]$. But more recent research has shown that this is due to a decrement of factors which influence the surrounding milieu, e.g. decreased growth factor levels [41]. This is likely to influence the ability of the satellite cells to proliferate and fuse and thus they are unable to influence many of the changes seen in sarcopenia, particularly changes in the myonuclear domain size. 
Unlike acute conditions resulting in muscle atrophy, aging and the development of sarcopenia occurs slowly. Nevertheless, the myonuclei have independent transcriptional ability to respond to local stimuli/signals [42]. In both atrophy and sarcopenia, the molecular control of muscle size involves a major negative regulator of muscle mass, as well as other pathways, albeit to different extents.

\subsection{The signalling pathways}

The molecular mechanisms underpinning muscle atrophy and ageing remain to be fully elucidated. The next section aims to describe a number of key molecular components and contributors to atrophy and ageing. In this book chapter we will review current accounts of three main contributors - myostatin, ubiquitin ligases MAFbx and MuRF1, and IGF1, AKTmTOR pathway.

\subsubsection{Myostatin/SMAD pathway and atrophy/sarcopenia}

Myostatin (growth-differentiation factor 8, GDF8] is a member of the transforming growth factor (TGF) $\beta$ superfamily and a negative regulator of muscle mass. Myostatin appears to be primarily found in muscle tissue [43]. Animals with a polymorphism in the myostatin gene, that renders it less active, experience hypertrophied muscles. This is seen in "double muscled" cattle [44-46], the significant hypertrophy in a child [47]and myostatin knock-out mice [43], all of which demonstrate significant hypertrophy in skeletal muscles in response to myostatin gene mutation. Even with a normal myostatin gene, if expression is blocked experimentally, there are $13-30 \%$ increases in skeletal muscle hypertrophy [48]. In evolutionary terms, it is well known that hominid size was not the crucial factor securing survival. Therefore, adequate control of muscle mass requires that hypertrophy be kept in check, and this negative regulator is myostatin.

Conversely, overexpression of myostatin leads to muscle atrophy [49]. Also, situations of muscle disuse in mammals typically lead to increased myostatin mRNA [50] and protein [51]. Myostatin inhibits muscle protein synthesis and growth as well as satellite cell differentiation [52,53].

Members of the TGF $\beta$ superfamily, including myostatin, bind to membrane receptors and trigger the phosphorylation and activation of the SMADs, a family of signal transducers [54]. Myostatin binds to activin type II receptors which results in recruitment of the type I receptor to the type II receptor-myostatin complex [55] and activation of regulatory SMADs (SMAD2 and SMAD3] [56]. These SMAD2 and SMAD3 complex with SMAD4 and together translocate to the nucleus where gene transcription is altered.

Studies investigating changes in myostatin levels with muscle atrophy have reported:

i. Spaceflight: increased myostatin transcript levels after 11 days of spaceflight in mice [57].

ii. Animal models: increased myostatin transcript levels as early as one day after hindlimb suspension [58]. 
iii. Bed rest in humans: 25 days of bed rest resulted in $12 \%$ greater serum myostatin levels [59].

iv. Unilateral lower limb suspension (ULLS) in humans: three days of ULLS led to increased myostatin transcript and protein levels [60].

Ageing muscle, again, has shown differing responses. Some authors have reported no relationship between myostatin mRNA levels and skeletal muscle mass [61,62] while others have shown an increase in myostatin levels along with decreased muscle mass in ageing individuals $[63,64]$.

To unravel the complex differences between atrophy and sarcopenia, it is necessary to understand other molecular pathways influencing muscle mass and how these may interact. Indeed, myostatin is thought to act through a number of pathways including upregulation of ubiquitin-proteasome pathway (including MAFbx and MuRF1]; interactions with FOXO, inhibition of AKT-mTOR pathway (see next sections); as well as inhibition of satellite cells (described earlier).

\subsubsection{Ubiquitin ligases $M A F b x / M u R F 1$ and atrophy/sarcopenia}

There are various molecular mechanisms involved in muscle wasting including calpain, caspase and ubiquitin mediated protein degradation. It is not within the scope of this chapter to discuss these in detail, however since the ATP-dependent ubiquitin proteasome pathway is the primary degradation pathway of skeletal muscle in response to inactivity and disuse, two components of this pathway must be discussed for their role in the assessment of the molecular process of skeletal muscle atrophy. The ubiquitin proteasome pathway is translationally upregulated during muscle atrophy. It involves E1 ligases which activate ubiquitin E2 ligases that are responsible for transferring the activated ubiquitin to the protein molecule that is then targeted for degradation, but still requires a further control step: the E3 ligases regulate the actual transfer of ubiquitin to the protein. Two important skeletal muscle specific ubiquitin E3 ligases are Muscle-specific RING Finger protein1 (MuRF1] and Muscle Atrophy F-box (MAFbx/atrogin-1].

MAFbx and MuRF1 have been identified as factors functioning to a great extent during muscle atrophy in several models of disuse [65]. MAFbx and MuRF1 were first identified following profiling in mouse atrophy after fasting and immobilisation $[65,66]$. The expression of both appears to be primarily in skeletal muscle. In knock-out models, animals which cannot make MAFbx and MuRF1 proteins, do not lose muscle mass with denervation [65].

MAFbx and MuRF1 mRNA levels are rapidly activated in numerous models of atrophy and are thought to contribute to the initiation of the atrophy process [67]:

i. Spaceflight: increased MAFbx and MuRF1 gene expression in rodents [57]

ii. Animal models: increased MAFbx and MuRF1 after hindlimb suspension [68]

iii. Unilateral lower limb suspension (ULLS) in humans: three days of ULLS led to increased MAFbx and MuRF1 transcript levels [60]; increased MuRF1 after 10 days ULLS and decreased MAFbx and MuRF1 10-21 days of ULLS [69]. 
iv. Immobilisation (cast or leg brace) in humans: increased MAFbx and MuRF1 gene expression after immobilization [70,71].

Studies on ageing animals have reported both increased [72] and decreased [73] MAFbx and MuRF1 levels. However, in ageing human muscle most studies report no changes in MAFbx or MuRF1 [eg [74]]. This may be due to the prolonged nature of the ageing stimulus, or the distinct lack of anabolic stimulus.

MAFbx and MuRF1 are regulated by the family of Forkhead box O (FOXO) transcription factors [75]. FOXO1 does not directly increase MAFbx or MuRF1. In rodent muscle, IGF1 which is pro-anabolic, inhibits the upregulation of these E3-ligases [75], however upregulation of FOXO1 blocks this influence of IGF1 and allows for the upregulation of MAFbx and MuRF1.

Nonetheless, human models of atrophy do not show the same relationship of FOXO with MAFbx and MuRF1 [eg [60]]. Therefore, to fully understand atrophy and sarcopenia, and before discussing the mechanisms behind potential interventions, it is necessary to elucidate an anabolic pathway, namely the IGF1-AKT-mTOR pathway.

\subsubsection{IGF1-AKT-mTOR and atrophy/sarcopenia}

Insulin-like growth factor 1 (IGF1] is a critical growth factor that promotes muscle hypertrophy in skeletal muscle. IGF1 acts through the AKT-mTOR pathway which plays a primarily role in skeletal muscle protein synthesis. IGF1 can stimulate the pathway via PI3K and AKT, but ultimately mTOR is the central governing signalling factor which modulates transcription via p70S6K, 4E-BP1, eIF4E and thus protein synthesis. When the AKT pathway is deactivated this leads to muscle atrophy through FOXO [76]. Animals with knock-out $\mathrm{AKT}$ genes have significant atrophy. In physiological models of atrophy the following has been reported:

i. Spaceflight: increased FOXO1 transcript levels, decreased insulin receptor substrate-1 (IRS-1] transcript levels after spaceflight in rodents [57]

ii. Animal models: 10 days of hindlimb suspension also led to decreased phosphorylation of AKT and p70S6K [77].

iii. Unilateral lower limb suspension (ULLS) in humans: no change in AKT-mTOR pathway components after 10 days or 21 days ULLS [78].

As mentioned in the previous section, there is an indirect connection between IGF1 and the E3 ligases. In cell culture, deactivation of IGF1-PI3K-AKT has been linked to increased levels of the ubiquitin proteasome E3 ligases, MAFbx and MuRF1 [79]. It is thought that AKT acts directly on FOXO. When growth stimuli are present, AKT acts to phosphorylate FOXO and the phosphorylated FOXO remains in the cytosol. When growth stimuli are removed, AKT is inactive which causes dephosphorylation of FOXO allowing it to relocate from the cytosol to the nucleus and activate genes involved in cell death, cell cycle inhibition and metabolism. Animals with overexpression of FOXO have reduced muscle mass and this appears to be related to increases in MAFbx and MuRF1. 
Alterations in IGF1 signalling pathways in older adults contributes to sarcopenia by means of influencing muscle fibre size, increased loss of myonuclei and increased proteolysis [reviewed in [80]]. Since IGF1 has been shown to control muscle mass in cell culture [81], it's relevance and contribution to age-related changes is fundamental. Indeed, increased total AKT (but not phosphorylated AKT) has been reported in ageing adults depicting a reduction in efficiency of AKT in older individuals [82].

Finally, in keeping with the multi-nucleated nature of muscle fibres and the control of myonuclear domain size, IGF1 also acts directly on satellite cells. It causes satellite cell proliferation and its absence is associated with lower proliferation capacity. Therefore, interventions that focus on the IGF1-AKT-mTOR pathway, will also induce activation of the support-system for addition of myonuclei.

\section{Methodological analysis and imaging of skeletal muscle changes with atrophy and sarcopenia (including human and animal models)}

\subsection{Cell Culture}

Cell culture, or in vitro methods, allow researchers to manipulate the environment in which the cells will live and grow. The cells are grown under extremely controlled conditions and this allows results to be obtained based on absolute control of the system, homogeneity of the sample and less compounds needed for analysis. Using cell culture models allows removal of confounding variables such as surrounding tissues or the effects of repeated stress on an animal or human. It also reduces the use of animals in research. However, disadvantages of cell culture include the cost of setting up the laboratories, maintaining the cell cultures and adding substances that simulate the controlled physiological conditions to the normal culture media. Cell culture provides a great insight into specific pathways (such as those discussed earlier) with addition of known major controllers such as myostatin, to the media. But this model can also provide evidence of the role of specific proteins and pathways by simple removal of specific molecules or the blocking of these by inhibitors or silencers.

Despite all these advantages, within the cell culture models, the cells will not react exactly as they would inside mammalian organism.

\subsection{Animal models}

There are a number of well characterized and representative animal models to investigate unloading and disuse atrophy, including hindlimb suspension (discussed above). Investigations using models of muscle disuse have yielded a large and important body of knowledge including details explained in this book chapter. However, it must always be remembered that while animal models provide insight and clarification of some of the complex signalling pathways and interactions which are underway during muscle atrophy and sarcopenia; there are a number of key differences which cast a slight shadow on the direct comparison of animal and human models. 
It is consistently observed and acknowledged that influences on protein synthesis and degradation are different in human and animal models, including a faster rate of muscle loss in rodent models and a differing response to unloading in slow and fast fibre types in animals compared to humans [reviewed in [83]]. In most animal studies investigating protein synthesis, the animals had not yet reached maturity and were still in the growth phase (albeit slow growth), which is not directly comparable with adult human beings. The response of animals to changes which occur with ageing is also not identical to that of the human response. A crucial issue that needs to be discussed in this regards, is when the ageing response begins in various animal species because this is key to interpretation of findings in animal studies.

Nevertheless, the benefits of animal studies are the insight which they provide for research development and strategies that will aid in knowledge development leading to clinical studies to prevent or alleviate skeletal muscle atrophy and improve muscle mass in humans, and should therefore not be dismissed.

\subsection{Human models}

The extensive benefit of studying skeletal muscle loss with human research projects is the direct applicability of the results with the potential to provide extremely useful information for individuals, communities and the greater body of scientific knowledge. Furthermore, with the advent of technologically advanced medical imaging facilities, analysis of skeletal muscle disuse and sarcopenia can be achieved to a greater degree of accuracy than before, and more non-invasively.

Magnetic resonance imaging (MRI): uses radio frequency pulses over a powerful magnetic field to image nuclei of the atoms at any depth inside any body tissue. MRI does not use ionizing radiation. The MRI builds two-dimensional images of internal body structures such as organs, soft tissue and bone, with good contrast between the tissues. MRI can measure loss of muscle mass as well as changes within the muscle such as fat infiltration. A further advantage is that the images can be stored digitally for later comparison of the same subject using the same landmarks.

Dual-energy X-ray Absorptiometry (DXA): provides an accurate measure of bone mineral density, with calculations of fat-free (lean body) and fat mass of an individual. The DXA uses two x-ray beams with differing energy levels which create an image of the density of different body tissues. After skeletal muscle atrophy, individuals will have a reduction in lean body mass and may also have an increased fat mass and alterations in bone mineral density. The advantage of this imaging tool is that these concurrent changes in other tissues can be assessed at the same time. This is highly relevant since skeletal muscle is not the only tissue exposed to the external environmental influences promoting muscle loss.

Computed Tomography (CT): uses x-rays to show cross-sectional (or slice) images of the body. Since the x-ray moves around the body, it provides more detail than a regular x-ray. It can be used for diagnostic purposes such as diagnoses of tumors. With disuse and/or sarcopenia the 
CT scan can measure cross-sectional area of the entire muscle or the muscles in a functional group, assess content/quality of the muscle based on protein content/density and measure fatty infiltrations and other changes in skeletal muscle occurring with atrophy and disuse.

Positron emission tomography (PET): looks at how the body functions, rather than the body's anatomy (CT and MRI). After the intake of a radioactive sugar, the PET scan shows the metabolic activity of the body and rapidly growing cells. Cells which consume more of the radioactive sugar will be detected as darker on the PET scan.

Skeletal muscle biopsies, small muscle samples taken from humans using minimally invasive methods under local anaesthetic, can provide substantial insight into molecular pathways and alterations in structural components as well as myonuclei and satellite cells after disuse and the long-lasting effects of sarcopenia (as discussed above).

Together, the benefits and discoveries made and clarified in cell culture, animal models and in human muscle tissue samples, combined with those gained from imaging in more holistic human studies, provide an essential and significant insight into the complex interplay of interactions within skeletal muscle with disuse and sarcopenia. Furthermore, the knowledge gained with these experimental techniques will provide an appreciation and clarification of ways to intervene to alleviate, reduce or treat skeletal muscle atrophy and sarcopenia.

\section{Prevention and/or alleviation with nutritional and exercise interventions}

Because of the complex interplay of neural, hormonal, physical and nutritional alterations which occur with both atrophy and sarcopenia, as well as the progress being made in understanding molecular and cellular pathways with atrophy and sarcopenia, there are numerous potential interventions which can be, and which have been, investigated to combat, alleviate or benefit skeletal muscle mass with disuse and ageing. A number of these will be discussed here.

\subsection{Exercise}

\subsubsection{Resistance exercise}

Resistance exercise increases muscle mass and by increasing the load placed on the muscle activates the AKT-mTOR pathway thereby increasing protein synthesis and reducing muscle atrophy. As little as one bout of resistance exercise has been reported to increase IGF1 gene expression [84]. In young individuals, resistance exercise leads to increased protein synthesis after 2-4 hours [85] and this increase is maintained for 24-48 $\mathrm{h}$ in untrained individuals [85].

In models of disuse, such as bed rest and immobilization, resistance exercise alone has been reported to reduce, but not completely alleviate muscle loss. Resistance exercise during 14 days of single leg immobilization was sufficient to preserve quadriceps muscle mass [86] and during bed rest exercise alone reduces loss in muscle mass [87]. 
Resistance exercise training appears to be the only consistent way to combat sarcopenia. Physical activity can help slow the ageing process and improve the quality of life for elderly individuals. Older adults respond well to load bearing activity and increases in strength, muscle size and function are repeatedly found with resistance exercise interventions even in very old individuals, both community dwelling and nursing home residents. Elderly individuals tolerate relatively high intensity resistance exercise and this shows the greatest responses. However, care should be taken when prescribing resistance exercise for elderly individuals taking into consideration other health complications. Resistance exercise training also restores ageing muscle's ability to increase nuclear domain size within hypertrophy [27]. Resistance exercise is thought to affect satellite cells and have a positive effect on age-related changes in satellite cells and myonuclei [reviewed in [88]].

\subsubsection{Endurance exercise}

Aerobic exercise such as inflight cycle ergometer in space or endurance exercise on earth helps to maintain and improve cardiovascular function [89], however because it has no mechanical loading, endurance exercise has no large effect on skeletal muscle mass and therefore does not reduce muscle atrophy or sarcopenia. Furthermore, the intensity of the endurance exercise must be sufficient to maintain aerobic fitness [90]. Since endurance exercise does show positive influences by enhancing muscle oxidative capacity in elderly individuals, combining an endurance modality with resistance exercise may add further benefits to the muscle.

\subsection{Pharmacological}

\subsubsection{Testosterone}

Testosterone has been shown to regulate skeletal muscle mass in humans [91] and anabolic steroids are known to increase muscle mass in healthy individuals by increasing protein synthesis and accelerating activation of satellite cells and interestingly administration of androgens increases satellite cell numbers in a dose-dependent manner [92,93]. This response is particularly noted when combined with load bearing exercise. However, physiologically relevant increases in testosterone do not appear to enhance protein synthesis following resistance exercise [94].

During sarcopenia, decreased circulating levels of testosterone and dehydroepiandroste (DHEA) are prevalent [95]. Studies have reported a relationship between serum testosterone levels and muscle strength in older men. Testosterone alone has shown equivocal results in elderly individuals. Increases in lean body mass, but not knee extensor strength has been reported [96] However, increases in muscle strength, muscle fibre size and satellite cell response after 20 weeks testosterone supplementation are promising in humans [97] and mice [98]. 


\subsection{Nutritional}

\subsubsection{Protein/essential Amino Acids}

Protein synthesis and degradation are influenced by nutrient intake and intake of proteins and amino acids (AA) stimulate muscle protein synthesis and inhibits protein breakdown [99]. In particular, leucine, an essential amino acid, is an especially powerful stimulator of protein synthesis by both insulin dependent and independent pathways. Carbohydrate and protein are known to stimulate protein synthesis and can positively influence IGF1-mTORAKT pathway to stimulate protein synthesis and prevent upregulation of FOXO, MuRF1 and MAFbx; therefore nutritional intake could be a powerful countermeasure in reducing muscle mass loss with disuse, particularly in situations where exercise is not feasible (such as hospitalized bed rest).

Essential AA supplementation has been consistently shown to influence protein synthesis and alleviate some, but not all, of the loss of skeletal muscle lost with bed rest [100], but not to the same extent as exercise. However, 28 days of immobilization with protein and amino acid supplementation [28g protein) did not prevent increases in myostatin, MuRF1 or MAFbx over time [101].

The post-absorptive rate of protein synthesis is similar in young and elderly individuals but elderly individuals may have a delayed anabolic sensitivity to amino acids compared to young individuals [102]. However, elderly individuals can still stimulate muscle protein synthesis with increased protein intake, and it also must be noted that many elderly individuals do not take in the recommended protein intake and this may contribute further to muscle mass loss [103]. Other nutritional interventions have produced positive results against sarcopenia, in particular, high quality protein diets may be beneficial for stimulating protein synthesis in the muscles of ageing individuals [104].

\subsubsection{Creatine}

Creatine supplementation has been reported to increase energy production, increase fat free and muscle mass. It has been reported to improve recovery after immobilization and to act, at least in part, through myogenic regulatory factors which influence satellite cells [105] and is therefore of interest to reduce muscle loss with clinically related atrophy as well as of potential interest in combatting sarcopenia with the elderly population.

However, older individuals appear to respond differently than young individuals to creatine supplementation [106]. Short term creatine supplementation in older adults has shown mixed results ranging from no effect [107-109] as well as increased anaerobic power and work capacity of sedentary older adults [108]. Short term creatine supplementation also has produced increases in strength and fat free mass of elderly men and women [110,111]. In longer studies, neither creatine supplementation, protein supplementation, or a combination of protein and creatine was shown to provide further benefit beyond 16 weeks of isotonic resistance training alone in elderly subjects [112]. However, a recent review on creatine 
supplementation and elderly individuals suggests that timing and dose may also play a critical role in response to supplementation [113]. Since creatine supplementation is a natural, inexpensive and as far as we know, safe supplementation; and since creatine supplementation may provide other benefits to elderly individuals such as improved cognitive ability [114] it continues to be a potential factor in interventions to alleviate sarcopenia.

\section{Summary}

In summary, this book chapter has aimed to summarise skeletal muscle changes with disuse atrophy and sarcopenia, which are both significant public health issues and potential burdens on society. This chapter has introduced and illustrated cellular and molecular changes which occur within skeletal muscle, particularly focusing on myonuclei, satellite cells, and various relevant signalling pathways including - myostatin/SMADs, ubiquitin proteasome pathway and IGF1-AKT-mTOR pathway. The full interactions and molecular underpinnings remain to be elucidated, but we have reviewed the current knowledge and accounts of these three main contributors. These pathways are complex, and furthermore interact with each other in important ways to modulate muscle protein synthesis, muscle degradation and maintenance/loss of muscle mass. The significant impact of varying and advanced methodological analyses have been reported and the influence of molecular analysis, cell culture models, animal models as well as tools to measure interventions in human research have been reviewed. Finally, a number of preventative strategies have been discussed which are promising for minimising muscle atrophy and sarcopenia. The combination of nutritional and pharmacological interventions combined with exercise are favourable, practical and feasible applications to successfully influence prevention and alleviation of atrophy and sarcopenia. Understanding the disuse-related changes and agerelated declines in muscle mass will provide insight into preventing and combatting sarcopenia. This will benefit by improving quality of life in the increasing numbers of elderly individuals as well as reducing the burden on the community and the healthcare system.

\section{Author details}

Naomi E. Brooks

Health and Exercise Sciences, School of Sport, University of Stirling, Scotland, UK

Kathryn H. Myburgh

Department of Physiological Sciences, Stellenbosch University, South Africa

\section{References}

[1] Lynch GS. Therapies for improving muscle function in neuromuscular disorders. Exerc Sport Sci Rev 2001;29(4):141-8. 
[2] Ferrando AA, Lane HW, Stuart CA, Davis-Street J, Wolfe RR. Prolonged bed rest decreases skeletal muscle and whole body protein synthesis. Am J Physiol 1996;270(4 Pt 1):E627-33.

[3] Narici MV, de Boer MD. Disuse of the musculo-skeletal system in space and on earth. Eur J Appl Physiol 2011;111(3):403-20.

[4] de Boer MD, Maganaris CN, Seynnes OR, Rennie MJ, Narici MV. Time course of muscular, neural and tendinous adaptations to 23 day unilateral lower-limb suspension in young men. J Physiol 2007;583(Pt 3):1079-91.

[5] Sargeant AJ, Davies CT, Edwards RH, Maunder C, Young A. Functional and structural changes after disuse of human muscle. Clin Sci Mol Med 1977;52(4):337-42.

[6] Tobin BW, Uchakin PN, Leeper-Woodford SK. Insulin secretion and sensitivity in space flight: diabetogenic effects. Nutrition 2002;18(10):842-8.

[7] Hikida RS, Van Nostran S, Murray JD, Staron RS, Gordon SE, Kraemer WJ. Myonuclear loss in atrophied soleus muscle fibers. Anat Rec 1997;247(3):350-4.

[8] Ryall JG, Schertzer JD, Lynch GS. Cellular and molecular mechanisms underlying agerelated skeletal muscle wasting and weakness. Biogerontol 2008;9(4):213-28.

[9] Dela F, Kjaer M. Resistance training, insulin sensitivity and muscle function in the elderly. Essays Biochem 2006;42:75-88.

[10] Lexell J, Downham D, Sjöström M. Distribution of different fibre types in human skeletal muscles. Fibre type arrangement in $\mathrm{m}$. vastus lateralis from three groups of healthy men between 15 and 83 years. J Neurol Sci 1986;72(2-3):211-22.

[11] Janssen I, Heymsfield SB, Wang ZM, Ross R. Skeletal muscle mass and distribution in 468 men and women aged 18-88 yr. J Appl Physiol 1985;89(1):81-8.

[12] Brooks SV, Faulkner JA. Skeletal muscle weakness in old age: underlying mechanisms. Med Sci Sports Exerc 1994;26(4):432-9.

[13] Tanaka H, Seals DR. Endurance exercise performance in Masters athletes: ageassociated changes and underlying physiological mechanisms. J Physiol 2008;586(1):5563.

[14] Metter EJ, Talbot LA, Schrager M, Conwit R. Skeletal muscle strength as a predictor of all-cause mortality in healthy men. J Gerontol 2002;57(10):B359-65.

[15] Miller SL, Wolfe RR. The danger of weight loss in the elderly. J Nutr Health Aging 2012;12(7):487-91.

[16] Conley KE, Cress ME, Jubrias SA, Esselman PC, Odderson IR. From muscle properties to human performance, using magnetic resonance. J Gerontol 1995;50:35-40.

[17] Hepple RT, Baker DJ, McConkey M, Murynka T, Norris R. Caloric restriction protects mitochondrial function with aging in skeletal and cardiac muscles. Rejuvenation Res 2006;9(2):219-22.

[18] Hall ZW, Ralston E. Nuclear domains in muscle cells. Cell 1989;59(5):771-2.

[19] Pavlath GK, Rich K, Webster SG, Blau HM. Localization of muscle gene products in nuclear domains. Nature 1989;337(6207):570-3.

[20] Moss FP, Leblond CP. Satellite cells as the source of nuclei in muscles of growing rats. Anat Rec 1971;170(4):421-35. 
[21] Bischoff R. A satellite cell mitogen from crushed adult muscle. Development Biol 1986;115(1):140-7.

[22] Moss FP, Leblond CP. Nature of dividing nuclei in skeletal muscle of growing rats. J Cell Biol 1970;44(2):459-62.

[23] Allen DL, Monke SR, Talmadge RJ, Roy RR, Edgerton VR. Plasticity of myonuclear number in hypertrophied and atrophied mammalian skeletal muscle fibers. J Appl Physiol 1995;78(5):1969-76.

[24] Kadi F, Thornell LE. Concomitant increases in myonuclear and satellite cell content in female trapezius muscle following strength training. Histochem Cell Biol 2000;113(2):99-103.

[25] Gundersen K, Bruusgaard JC. Nuclear domains during muscle atrophy: nuclei lost or paradigm lost? J Physiol 2008;586(Pt 11):2675-81.

[26] Bruusgaard JC, Gundersen K. In vivo time-lapse microscopy reveals no loss of murine myonuclei during weeks of muscle atrophy. J Clin Invest 2008;118(4):1450-7.

[27] Hikida RS, Staron RS, Hagerman FC, Walsh S, Kaiser E, Shell S, et al. Effects of highintensity resistance training on untrained older men. II. Muscle fiber characteristics and nucleo-cytoplasmic relationships. J Gerontol 2000 J;55(7):B347-54.

[28] Brack AS, Bildsoe H, Hughes SM. Evidence that satellite cell decrement contributes to preferential decline in nuclear number from large fibres during murine age-related muscle atrophy. J Cell Sci 2005 118(Pt 20):4813-21.

[29] Burleigh IG. Observations on the number of nuclei within the fibres of some red and white muscles. J Cell Sci 1977;23:269-84.

[30] Edgerton VR, Roy RR. Regulation of skeletal muscle fiber size, shape and function. J Biomech 1991;24(Suppl 1)::123-33.

[31] Tseng BS, Kasper CE, Edgerton VR. Cytoplasm-to-myonucleus ratios and succinate dehydrogenase activities in adult rat slow and fast muscle fibers. Cell Tiss Res 1994;275(1):39-49.

[32] Booth FW, Thomason DB. Molecular and cellular adaptation of muscle in response to exercise: perspectives of various models. Physiol Rev 1991;71(2):541-85.

[33] Roy RR, Bodine SC, Pierotti DJ, Kim JA, Talmadge RJ, Barkhoudarian G, et al. Fiber size and myosin phenotypes of selected Rhesus hindlimb muscles after a 14-day spaceflight. J Gravit Physiol 1999;6(2):55-62.

[34] Brooks NE, Schuenke MD, Hikida RS. Ageing influences myonuclear domain size differently in fast and slow skeletal muscle of rats. Acta Physiol 2009;197(1):55-63.

[35] Gibson MC, Schultz E. Age-related differences in absolute numbers of skeletal muscle satellite cells. Muscle Nerve 1983;6(8):574-80.

[36] Kadi F, Charifi N, Denis C, Lexell J. Satellite cells and myonuclei in young and elderly women and men. Muscle Nerve 2004;29(1):120-7.

[37] Renault V, Thornell L-E, Eriksson P-O, Butler-Browne G, Mouly V, Thorne L-E. Regenerative potential of human skeletal muscle during aging. Aging Cell 2002 Dec;1(2):132-9. 
[38] Roth SM, Martel GF, Ivey FM, Lemmer JT, Metter EJ, Hurley BF, et al. Skeletal muscle satellite cell populations in healthy young and older men and women. Anat Rec 2000;260(4):351-8.

[39] Gallegly JC, Turesky NA, Strotman BA, Gurley CM, Peterson CA, Dupont-Versteegden EE. Satellite cell regulation of muscle mass is altered at old age. J Appl Physiol 2004;97(3):1082-90.

[40] Schultz E, Lipton BH. Skeletal muscle satellite cells: changes in proliferation potential as a function of age. Mech Ageing Dev 1982;20(4):377-83.

[41] Conboy IM, Conboy MJ, Wagers AJ, Girma ER, Weissman IL, Rando TA. Rejuvenation of aged progenitor cells by exposure to a young systemic environment. Nature 2005;433(7027):760-4.

[42] Newlands S, Levitt LK, Robinson CS, Karpf AB, Hodgson VR, Wade RP, et al. Transcription occurs in pulses in muscle fibers. Genes Devel 1998;12(17):2748-58.

[43] McPherron AC, Lawler AM, Lee SJ. Regulation of skeletal muscle mass in mice by a new TGF-beta superfamily member. Nature 1997;387(6628):83-90.

[44] Grobet L, Martin LJ, Poncelet D, Pirottin D, Brouwers B, Riquet J, et al. A deletion in the bovine myostatin gene causes the double-muscled phenotype in cattle. Nature Genetics 1997;17(1):71-4.

[45] Kambadur R, Sharma M, Smith TP, Bass JJ. Mutations in myostatin (GDF8) in doublemuscled Belgian Blue and Piedmontese cattle. Genome Res 1997;7(9):910-6.

[46] McPherron AC, Lee SJ. Double muscling in cattle due to mutations in the myostatin gene. Proc Nat Acad Sci 1997;94(23):12457-61.

[47] Schuelke M, Wagner KR, Stolz LE, Hübner C, Riebel T, Kömen W, et al. Myostatin mutation associated with gross muscle hypertrophy in a child. $\mathrm{N}$ Eng J Med 2004;350(26):2682-8.

[48] Whittemore L-A, Song K, Li X, Aghajanian J, Davies M, Girgenrath S, et al. Inhibition of myostatin in adult mice increases skeletal muscle mass and strength. Biochem Biophys Res Comm 2003;300(4):965-71.

[49] Reisz-Porszasz S, Bhasin S, Artaza JN, Shen R, Sinha-Hikim I, Hogue A, et al. Lower skeletal muscle mass in male transgenic mice with muscle-specific overexpression of myostatin. Am J Physiol 2003;285(4):E876-88.

[50] Reardon KA, Davis J, Kapsa RM, Choong P, Byrne E. Myostatin, insulin-like growth factor-1, and leukemia inhibitory factor mRNAs are upregulated in chronic human disuse muscle atrophy. Muscle Nerve 2001;24(7):893-9.

[51] Shao C, Liu M, Wu X, Ding F. Time-dependent expression of myostatin RNA transcript and protein in gastrocnemius muscle of mice after sciatic nerve resection. Microsurgery 2007;27(5):487-93.

[52] Langley B, Thomas M, Bishop A, Sharma M, Gilmour S, Kambadur R. Myostatin inhibits myoblast differentiation by down-regulating MyoD expression. J Biol Chem 2002;277(51):49831-40.

[53] Zimmers TA, Davies MV, Koniaris LG, Haynes P, Esquela AF, Tomkinson KN, et al. Induction of cachexia in mice by systemically administered myostatin. Science 2002;296(5572):1486-8. 
[54] Zhu X, Topouzis S, Liang L-F, Stotish RL. Myostatin signaling through Smad2, Smad3 and Smad4 is regulated by the inhibitory Smad7 by a negative feedback mechanism. Cytokine 2004;26(6):262-72.

[55] Tsuchida K, Nakatani M, Yamakawa N, Hashimoto O, Hasegawa Y, Sugino H. Activin isoforms signal through type I receptor serine/threonine kinase ALK7. Mol Cell Endocrinol 2004;220(1-2):59-65.

[56] Tsuchida K, Nakatani M, Matsuzaki T, Yamakawa N, Liu Z, Bao Y, et al. Novel factors in regulation of activin signaling. Mol Cell Endocrinol 2004;225(1-2):1-8.

[57] Allen DL, Bandstra ER, Harrison BC, Thorng S, Stodieck LS, Kostenuik PJ, et al. Effects of spaceflight on murine skeletal muscle gene expression. J Appl Physiol 2009;106(2):582-95.

[58] Carlson CJ, Booth FW, Gordon SE. Skeletal muscle myostatin mRNA expression is fiber-type specific and increases during hindlimb unloading. Am J Physiol 1999;277(2 Pt 2):R601-6.

[59] Zachwieja JJ, Smith SR, Sinha-Hikim I, Gonzalez-Cadavid N, Bhasin S. Plasma myostatin-immunoreactive protein is increased after prolonged bed rest with low-dose T3 administration. J Gravitational Physiol 1999;6(2):11-5.

[60] Gustafsson T, Osterlund T, Flanagan JN, von Waldén F, Trappe T A, Linnehan RM, et al. Effects of 3 days unloading on molecular regulators of muscle size in humans. J Appl Physiol 2010;109(3):721-7.

[61] Marcell TJ, Harman SM, Urban RJ, Metz DD, Rodgers BD, Blackman MR. Comparison of GH, IGF-I, and testosterone with mRNA of receptors and myostatin in skeletal muscle in older men. Am J Physiol 2001;281(6):E1159-64.

[62] Ratkevicius A, Joyson A, Selmer I, Dhanani T, Grierson C, Tommasi AM, et al. Serum concentrations of myostatin and myostatin-interacting proteins do not differ between young and sarcopenic elderly men. J Gerontol 2011;66(6):620-6.

[63] Schulte JN, Yarasheski KE. Effects of resistance training on the rate of muscle protein synthesis in frail elderly people. Int J Spo Nutr Exerc Metab 2001:11(Suppl);S111-8.

[64] Yarasheski KE, Bhasin S, Sinha-Hikim I, Pak-Loduca J, Gonzalez-Cadavid NF. Serum myostatin-immunoreactive protein is increased in 60-92 year old women and men with muscle wasting. J Nutr Health Aging 2002;6(5):343-8.

[65] Bodine SC, Latres E, Baumhueter S, Lai VK, Nunez L, Clarke B A, et al. Identification of ubiquitin ligases required for skeletal muscle atrophy. Science 2001;294(5547):1704-8.

[66] Gomes MD, Lecker SH, Jagoe RT, Navon A, Goldberg AL. Atrogin-1, a muscle-specific F-box protein highly expressed during muscle atrophy. Proc Nat Acad Sci 2001;98(25):14440-5.

[67] Foletta VC, White LJ, Larsen AE, Léger B, Russell AP. The role and regulation of MAFbx/atrogin-1 and MuRF1 in skeletal muscle atrophy. Pflügers Archiv: Eur J Physiol 2011;461(3):325-35.

[68] Dupont-Versteegden EE, Fluckey JD, Knox M, Gaddy D, Peterson CA. Effect of flywheel-based resistance exercise on processes contributing to muscle atrophy during unloading in adult rats. J Appl Physiol 2006;101(1):202-12. 
[69] de Boer MD, Selby A, Atherton P, Smith K, Seynnes OR, Maganaris CN, et al. The temporal responses of protein synthesis, gene expression and cell signalling in human quadriceps muscle and patellar tendon to disuse. J Physiol 2007;585(Pt 1):241-51.

[70] Jones SW, Hill RJ, Krasney PA, O'Conner B, Peirce N, Greenhaff PL. Disuse atrophy and exercise rehabilitation in humans profoundly affects the expression of genes associated with the regulation of skeletal muscle mass. FASEB J 2004;18(9):1025-7.

[71] Abadi A, Glover EI, Isfort RJ, Raha S, Safdar A, Yasuda N, et al. Limb immobilization induces a coordinate down-regulation of mitochondrial and other metabolic pathways in men and women. PloS One 2009;4(8):e6518.

[72] Clavel S, Coldefy A-S, Kurkdjian E, Salles J, Margaritis I, Derijard B. Atrophy-related ubiquitin ligases, atrogin-1 and MuRF1 are up-regulated in aged rat Tibialis Anterior muscle. Mech Age Dev 2006;127(10):794-801.

[73] Edström E, Altun M, Hägglund M, Ulfhake B. Atrogin-1/MAFbx and MuRF1 are downregulated in aging-related loss of skeletal muscle. J Gerontol 2006;61(7):663-74.

[74] Whitman SA, Wacker MJ, Richmond SR, Godard MP. Contributions of the ubiquitinproteasome pathway and apoptosis to human skeletal muscle wasting with age. Pflügers Archiv: Eur J Physiol 2005;450(6):437-46.

[75] Stitt TN, Drujan D, Clarke BA, Panaro F, Timofeyva Y, Kline WO, et al. The IGF1/PI3K/Akt pathway prevents expression of muscle atrophy-induced ubiquitin ligases by inhibiting FOXO transcription factors. Molecular Cell 2004;14(3):395-403.

[76] Sandri M, Sandri C, Gilbert A, Skurk C, Calabria E, Picard A, et al. Foxo transcription factors induce the atrophy-related ubiquitin ligase atrogin-1 and cause skeletal muscle atrophy. Cell 2004;117(3):399-412.

[77] Sugiura T, Abe N, Nagano M, Goto K, Sakuma K, Naito H, et al. Changes in PKB/Akt and calcineurin signaling during recovery in atrophied soleus muscle induced by unloading. Am J Physiol 2005;288(5):R1273-8.

[78] de Boer MD, Selby A, Atherton P, Smith K, Seynnes OR, Maganaris CN, et al. The temporal responses of protein synthesis, gene expression and cell signalling in human quadriceps muscle and patellar tendon to disuse. J Physiol 2007;585(Pt 1):241-51.

[79] Kandarian SC, Jackman RW. Intracellular signaling during skeletal muscle atrophy. Muscle Nerve 2006;33(2):155-65.

[80] Perrini S, Laviola L, Carreira MC, Cignarelli A, Natalicchio A, Giorgino F. The GH/IGF1 axis and signaling pathways in the muscle and bone: mechanisms underlying agerelated skeletal muscle wasting and osteoporosis. J Endocrinol 2010;205(3):201-10.

[81] Rommel C, Bodine SC, Clarke BA, Rossman R, Nunez L, Stitt TN, et al. Mediation of IGF-1-induced skeletal myotube hypertrophy by $\mathrm{PI}(3) \mathrm{K} / \mathrm{Akt} / \mathrm{mTOR}$ and PI(3)K/Akt/GSK3 pathways. Nature Cell Biol 2001 2001;3(11):1009-13.

[82] Léger B, Derave W, De Bock K, Hespel P, Russell AP. Human sarcopenia reveals an increase in SOCS-3 and myostatin and a reduced efficiency of Akt phosphorylation. Rejuvenation Res 2008;11(1):163-175B.

[83] Phillips SM, Glover EI, Rennie MJ. Alterations of protein turnover underlying disuse atrophy in human skeletal muscle. J Appl Physiol 2009;107(3):645-54. 
[84] Chesley A, MacDougall JD, Tarnopolsky MA, Atkinson SA, Smith K. Changes in human muscle protein synthesis after resistance exercise. J Appl Physiol 1992;73(4):1383-8.

[85] Phillips SM, Tipton KD, Aarsland A, Wolf SE, Wolfe RR. Mixed muscle protein synthesis and breakdown after resistance exercise in humans. Am J Physiol 1997;273(1 Pt 1):E99-107.

[86] Oates BR, Glover EI, West DW, Fry JL, Tarnopolsky M a, Phillips SM. Low-volume resistance exercise attenuates the decline in strength and muscle mass associated with immobilization. Muscle Nerve 2010;42(4):539-46.

[87] Ferrando AA, Tipton KD, Bamman MM, Wolfe RR. Resistance exercise maintains skeletal muscle protein synthesis during bed rest. J Appl Physiol 1997;82(3):807-10.

[88] Snijders T, Verdijk LB, van Loon LJC. The impact of sarcopenia and exercise training on skeletal muscle satellite cells. Ageing Res Rev. 2009;8(4):328-38.

[89] Chase GA, Grave C, Rowell LB. Independence of changes in functional and performance capacities attending prolonged bed rest. Aerospace Med 1966;37(12):12328.

[90] Suzuki Y, Kashihara H, Takenaka K, Kawakubo K, Makita Y, Goto S, et al. Effects of daily mild supine exercise on physical performance after 20 days bed rest in young persons. Acta Astron 1994;33:101-11.

[91] Herbst KL, Bhasin S. Testosterone action on skeletal muscle. Curr Opin Clin Nutr Metab Care 2004;7(3):271-7.

[92] Altuwaijri S, Lee DK, Chuang K-H, Ting H-J, Yang Z, Xu Q, et al. Androgen receptor regulates expression of skeletal muscle-specific proteins and muscle cell types. Endocrine 2004;25(1):27-32.

[93] Sinha-Hikim I, Taylor WE, Gonzalez-Cadavid NF, Zheng W, Bhasin S. Androgen receptor in human skeletal muscle and cultured muscle satellite cells: up-regulation by androgen treatment. J Clin Endocrin Metab 2004;89(10):5245-55.

[94] West DWD, Kujbida GW, Moore DR, Atherton P, Burd NA, Padzik JP, et al. Resistance exercise-induced increases in putative anabolic hormones do not enhance muscle protein synthesis or intracellular signalling in young men. J Physiol 2009;587(Pt 21):5239-47.

[95] Matsumoto AM. Andropause: clinical implications of the decline in serum testosterone levels with aging in men. J Gerontol 2002;57(2):M76-99.

[96] Snyder PJ, Peachey H, Hannoush P, Berlin JA, Loh L, Lenrow DA, et al. Effect of testosterone treatment on body composition and muscle strength in men over 65 years of age. J Clin Endocrin Metab 1999;84(8):2647-53.

[97] Sinha-Hikim I, Cornford M, Gaytan H, Lee ML, Bhasin S. Effects of testosterone supplementation on skeletal muscle fiber hypertrophy and satellite cells in communitydwelling older men. J Clin Endocrin Metab 2006;91(8):3024-33.

[98] Kovacheva EL, Hikim APS, Shen R, Sinha I, Sinha-Hikim I. Testosterone supplementation reverses sarcopenia in aging through regulation of myostatin, c-Jun NH2-terminal kinase, Notch, and Akt signaling pathways. Endocrinology 2010;151(2):628-38. 
[99] Rennie MJ, Edwards RH, Halliday D, Matthews DE, Wolman SL, Millward DJ. Muscle protein synthesis measured by stable isotope techniques in man: the effects of feeding and fasting. Clin Sci 1982;63(6):519-23.

[100] Paddon-Jones D, Sheffield-Moore M, Urban RJ, Sanford AP, Aarsland A, Wolfe RR, et al. Essential amino acid and carbohydrate supplementation ameliorates muscle protein loss in humans during 28 days bedrest. J Clin Endo Metab 2004;89(9):4351-8.

[101] Bunn J a, Buford TW, Serra MC, Kreider RB, Willoughby DS. Protein and amino acid supplementation does not alter proteolytic gene expression following immobilization. J Nutr Metab 2011;2011:539690.

[102] Drummond MJ, Dreyer HC, Pennings B, Fry CS, Dhanani S, Dillon EL, et al. Skeletal muscle protein anabolic response to resistance exercise and essential amino acids is delayed with aging. J Appl Physiol 2008;104(5):1452-61.

[103] Campbell WW, Evans WJ. Protein requirements of elderly people. Eur J Clin Nutr 1996;50(Suppl 1):S180-3.

[104] Symons TB, Sheffield-Moore M, Wolfe RR, Paddon-Jones D. A moderate serving of high-quality protein maximally stimulates skeletal muscle protein synthesis in young and elderly subjects. J Am Diet Assoc 2009;109(9):1582-6.

[105] Hespel P, Op't Eijnde B, Van Leemputte M, Ursø B, Greenhaff PL, Labarque V, et al. Oral creatine supplementation facilitates the rehabilitation of disuse atrophy and alters the expression of muscle myogenic factors in humans. J Physiol 2001;536(Pt 2):625-33.

[106] Rawson ES, Clarkson PM, Price TB, Miles MP. Differential response of muscle phosphocreatine to creatine supplementation in young and old subjects. Acta Physiol 2002;174(1):57-65.

[107] Rawson ES, Clarkson PM. Acute creatine supplementation in older men. Int J Sports Med 2000;21(1):71-5.

[108] Wiroth JB, Bermon S, Andreï S, Dalloz E, Hébuterne X, Dolisi C. Effects of oral creatine supplementation on maximal pedalling performance in older adults. Eur J Appl Physiol 2001;84(6):533-9.

[109] Jakobi JM, Rice CL, Curtin SV, Marsh GD. Neuromuscular properties and fatigue in older men following acute creatine supplementation. Eur J Appl Physiol 2001;84(4):3218.

[110] Gotshalk LA, Volek JS, Staron RS, Denegar CR, Hagerman FC, Kraemer WJ. Creatine supplementation improves muscular performance in older men. Med Sci Sports Exerc 2002;34(3):537-43.

[111] Gotshalk LA, Kraemer WJ, Mendonca MAG, Vingren JL, Kenny AM, Spiering BA, et al. Creatine supplementation improves muscular performance in older women. Eur J Appl Physiol 2008;102(2):223-31.

[112] Carter JM, Bemben DA, Knehans AW, Bemben MG, Witten MS. Does nutritional supplementation influence adaptability of muscle to resistance training in men aged 48 to 72 years. J Geriat Phys 2005;28(2):40-7.

[113] Candow DG. Sarcopenia: current theories and the potential beneficial effect of creatine application strategies. Biogerontology 2011;12(4):273-81. 
[114] Rawson ES, Venezia AC. Use of creatine in the elderly and evidence for effects on cognitive function in young and old. Amino Acids 2011;40(5):1349-62.

[115] Brooks NE, Cadena SM, Vannier E, Cloutier G, Carambula S, Myburgh KH, et al. Effects of resistance exercise combined with essential amino acid supplementation and energy deficit on markers of skeletal muscle atrophy and regeneration during bed rest and active recovery. Muscle Nerve 2010;42(6):927-35. 